\title{
Knowledge, Treatment, Control, and Risk Factors for Hypertension among Adults in Southern Iran
}

\author{
Sayed Fazel Zinat Motlagh, ${ }^{1}$ Reza Chaman, ${ }^{2}$ Sayed Rashid Ghafari, ${ }^{1}$ Zafar Parisay, \\ Mohamad Reza Golabi, ${ }^{1}$ Ahmad Ali Eslami, ${ }^{3}$ and Amin Babouei ${ }^{1}$ \\ ${ }^{1}$ Social Determinants of Health Research Center, Yasuj University of Medical Sciences, Yasuj, Iran \\ ${ }^{2}$ Department of Community Medicine, School of Medicine, Yasuj University of Medical Sciences, Yasuj, Iran \\ ${ }^{3}$ Department of Health Education and Promotion, School of Health, Isfahan University of Medical Sciences, Isfahan, Iran \\ Correspondence should be addressed to Ahmad Ali Eslami; eslamiaa@gmail.com
}

Received 16 July 2015; Revised 22 October 2015; Accepted 2 November 2015

Academic Editor: Hualiang Lin

Copyright (c) 2015 Sayed Fazel Zinat Motlagh et al. This is an open access article distributed under the Creative Commons Attribution License, which permits unrestricted use, distribution, and reproduction in any medium, provided the original work is properly cited.

\begin{abstract}
Hypertension is the first and the most common risk factor to diseases such as cardiovascular, stroke, and renal diseases. The aim of this study was to determine the factors relevant to hypertension knowledge, treatment, and control in southern Iran. In this cross-sectional study, conducted in Kohgiluye Boyer-Ahmad province, south of Iran, a total of 1836 hypertension patients were randomly selected to participate voluntarily in the study. Hypertension treatment and its control were defined during study. In addition, knowledge about hypertension was measured by hypertension knowledge level scale (HK-LS). Treatment rates were 75.5 and 37.7 percent for female and male, respectively. Habitat, education, income, family history with hypertension, smoking, and time of diagnosis to the disease were found to be related to the treatment of the disease. Control rates were 30.7 and 31.4 for males and females, respectively. Habitat, education, and time of diagnosis to the disease were related to control. Over 50 percent of patients had average knowledge on hypertension. Considering the low rate of control and knowledge on hypertension among patients, health care providers should reinforce their services to improve appropriate knowledge level among elders and, also, plan comprehensive programs to promote health in order to encourage patients change and reform their life style.
\end{abstract}

\section{Introduction}

Rapid rise of noncommunicable diseases has been considered as a major health challenge in the present century, which threatens social and economic development of communities and people health [1]. Such diseases impose half of the burden of diseases cost in the world [2-4]. Following the present trend, it is predicted that patients will be responsible for over 70 percent of diseases by $2020[1,4,5]$. In this regard, hypertension has been considered as the first and the most common risk factor to cardiovascular diseases, stroke, and renal diseases; it has been known as a main modulated disability cause around the world $[6,7]$ so that hypertension caused at least 45 percent of mortality due to cardiovascular problems and 51 percent of stroke mortality rate [8]. Among 17 million deaths due to cardiovascular problems in the world
[8], 9.4 million occur as a consequence of complications of hypertension [9]. In this regard, in Eastern Mediterranean Region where Iran is located, 26 percent of mortality results from hypertension [10].

On the other hand, statistics showed an increase in the prevalence of hypertension. The number of patients with hypertension has increased from 600 million cases in 1980 to 1 billion in 2008; over 40 percent of adults were known to have hypertension [11]. Also, it was suggested that, by 2025, 1.54 billion adults will suffer from hypertension [12]. In this regard, it was reported to be 14 to 34 percent in Iran [13-18] and various studies in other countries reported high rates of hypertension from 18 to 72 percent among males and females [19-27].

It is essential to control hypertension to minimize the side effects of hypertension. Rates reported for hypertension 
control were disappointing [28], which were suggested to be 13 to 56 percent around the world $[23,26,29,30]$. An important component to control hypertension is knowledge, which is relative to lower rates of ceasing interventions, following the interventions behavior and better control on disease by patients. As a result, careful evaluation of hypertension has been considered as an inseparable part of general care of the patients [31].

Studies suggested low levels of knowledge on hypertension among patients $[23,24,32]$, and lack of correct information and improper understanding of hypertension did not appertain to rural sites; it has been widely reported in urban environments and industrial countries, too [33, 34]. In Iran, studies on knowledge, treatment, and control of hypertension suggested low levels of the mentioned factors $[15,16]$. In Isfahan healthy heart program, the effects of comprehensive self-care programs on improving knowledge, attitude, and treatment among patients with hypertension were investigated. The results from the program showed that factors such as knowledge, treatment pursuit, and hypertension control were $49.9,43.8$, and 15.8 percent, respectively [16]. Another study reported treatment and hypertension control as 33.35 and 35.10 percent [15].

Considering factors related to knowledge and hypertension management is an essential starting point to preventing high rates of cardiovascular mortality due to hypertension [35]. However, there is little information available on knowledge, treatment, and control of hypertension in southern Iran. Noticing the importance of the topic, the aim of this study was to determine the factors relevant to hypertension knowledge, treatment, and control in southern Iran.

\section{Methods}

2.1. Participants. This cross-sectional study was conducted on a sample of men and women with hypertension in urban and rural health centres in Kohgiluyeh and BoyerAhmad Province in southern Iran, in 2014. Patients met the inclusion criteria (six months past the definitive diagnosis disease doctor, a record in health centres, over the age of 30). To participate in the study the patients were invited by phone or visiting their location. Participants who could not communicate effectively with the study personnel or provide informed consent were excluded. Finally, out of the 2,400 patients invited to study, 1836 (76.52\%) signed the consent form and voluntarily agreed to participate in the study.

2.2. Measures. Questionnaire included three sections that comprised the following questions: sociodemographic characteristics, hypertension-related information, and hypertension knowledge.

2.2.1. Sociodemographic Characteristics Variables. Sociodemographic data included data on age, gender, educational level (illiterate, elementary school, middle school, high school, diploma, and university), monthly family income (>5 million rials, 5 million rials to 10 million rials, 10 million rials to 15 million rials, and $<15$ million rials), marital status (single, married, divorced, or widowed/widower), employment status which was coded in 5 categories (employed, unemployed, farmer, retired, and housekeeper), physical activity, and smoking. (For smoking and hookah, nonsmoker and smoker were distinguished.)

Body Mass Index. Height (height was evaluated with an error close to $0.1 \mathrm{~cm}$, using a SECA portable stadiometer with the individual in the standing position) and weight (weight measurements were taken with participants wearing light clothing and no shoes; weight was measured with an error close to $0.5 \mathrm{Kg}$ using a SECA digital scale) were recorded by a nurse. Body mass index (BMI; calculated as weight/height ${ }^{2}$ ) was divided into 4 categories: below normal weight $(\mathrm{BMI}<$ 18.5), normal weight $(18.5 \leq \mathrm{BMI}<25.0)$, overweight $(25.0 \leq$ $\mathrm{BMI}<30.0)$, and obese $(\mathrm{BMI} \geq 30.0)[36]$.

2.2.2. Hypertension-Related Information. Hypertensionrelated questions included duration of hypertension, family history of HTN, and treatment of HTN which was defined as self-reported current use of antihypertensive medication. Control of HTN was defined as hypertensive participants' SBP $<140 \mathrm{~mm} \mathrm{Hg}$ and DBP $<90 \mathrm{~mm} \mathrm{Hg}$ among hypertensive participants who treated their HTN with drugs; that is, control in treatment was also analyzed. Hypertension was defined as systolic blood pressure (SBP) $\mathrm{C} 140 \mathrm{~mm} \mathrm{Hg}$ or diastolic blood pressure (DBP) C90 mm Hg according to the WHO criteria or history of previously diagnosed disease [37]; BP was measured in a sitting position after a minimum of 5 minutes of rest by using a standardized digital BP measuring machine (Omron Digital).

2.2.3. Hypertension Knowledge. Hypertension knowledge was ascertained by using Hypertension Knowledge Level Scale (HK-LS). This tool was developed from the Hypertension Knowledge Level Scale (HK-LS), a 22-item scale prepared by Erkoc et al. [37]. Hypertension Knowledge Level Scale (HK-LS) assessed respondents' knowledge in defining hypertension, lifestyle, medical treatment, drug compliance, diet, and complication of hypertension. Each item was a full sentence that was either correct or incorrect. And each item was prepared as part of a standard answer (correct, incorrect, or do not know). To assess the content validity of the scale to identify whether items were or were not representative of the knowledge level of hypertension, the opinions of experts were requested via an assessment form. The expert opinions were evaluated, and 2 items were excluded from the scale. All items were evaluated in terms of clarity and expression by considering the expert opinions, and relevant changes (definition (1 item), medical treatment (4 items), drug compliance (4 items), lifestyle (4 items), diet (2 items), and complications (5 items)) were made.

2.3. Statistical Analysis. Statistical analyses were performed using SPSS windows version 21.0 software (SPSS Inc., Chicago, Illinois, USA). $P$ value $<0.05$ was considered significant. 


\section{Results}

The mean age of respondents was 66.26 years [SD: 12.36], ranging from 30 to 93 years. Almost, 722 participants were male (39.3\%) and 1114 were female (60.7\%). More than half of the participants (51.5\%) were older than 60. Furthermore, 822 participants (44.8\%) were living in cities and 1014 (55.2\%) were living in villages. Regarding education, 1149 (66.2\%) were illiterate, $362(19.7 \%)$ were at elementary levels, 114 (6.2\%) were at guidance level, $46(2.5 \%)$ were at high school level, $90(4.9 \%)$ finished high school, and 75 (4.1\%) had academic education. With respect to marital status, 1488 participants (81\%) were married. 191 (17.6\%) were widows and $25(1.4 \%)$ were single. Over 90 percent of participants had low income. In addition, 45.5 percent reported family history of hypertension. Also, 27.5 percent of the respondents reported regular physical activity (Table 1).

3.1. Hypertension Treatment and Control. As shown in Table 1, 222 male (30.7\%) and 350 (31.4\%) participants reported self-control on their hypertension. There was no significant difference between male and female participants $(P=0.796)$, though it was higher among females. There was a statistically significant correlation between habitat $(P=$ $0.000)$, education $(P=0.000)$, income $(P=0.002)$, family history on hypertension $(P=0.003)$, smoking $(P=0.006)$, and diagnosis time $(P=0.045)$. Participants living in cities, with higher education and income levels, showed better control on their hypertension.

Treatment rate was high among participants. The treatment rates were $75.5 \%$ and $37.7 \%$ for females and males, respectively, while there was no statistically significant correlation between male and female participants $(P=0.383)$. 36.1 percent of participants who were under treatment showed regular use of their medications. 24.4 percent of participants under treatment reported control on their hypertension. There was a statistically significant correlation between age $(P=0.000)$, habitat $(P=0.019)$, education $(P=0.004)$, and diagnosis time $(P=0.045)$.

3.2. Knowledge. Table 2 represents patient's knowledge about hypertension. In general, 25.2 percent of participants showed high knowledge on hypertension (definition of hypertension, treatment pursuit, lifestyle, nutrition, and hypertension side effects).

This parameter was higher among male in comparison to females, participants with higher income in comparison to those with low incomes, among employees in comparison to other occupations, and among those with regular physical activities which was statistically meaningful.

\section{Discussion}

Improving knowledge, treatment, and control on hypertension could decrease high rates of mortality by cardiovascular diseases [38]. Results from our study showed that over half of the participants in the study were over 60 years old. Several studies reported a direct significance in the prevalence of hypertension and age, which corresponded to the results from the present study $[14,39-42]$. The results, also, suggested higher hypertension risk with elders. Therefore, it seems essential to plan preventive interventions to control hypertension among older people. Results from the present study reported that hypertension remains mostly undiagnosed during the early years of prevalence so that over 45 percent of patients over 60 were diagnosed for hypertension less than 5 years ago, which suggest the careful consideration of screening and increasing public knowledge on hypertension and its symptoms.

Our results indicated treatment and control rates on hypertension to be 74.8 and 31.2 percent, which were higher in comparison to the results by Esteghamati et al. [16] (2007) in Isfahan where treatment and control on hypertension were 43.8 and 15.8 percent, respectively. This increase could result from implementing Family Physician program and offering health care services to the patients in Iran.

Chow et al. (2013) reported that the rate of treatment and control of hypertension in high-, average-, and poorincome countries is low [43]; results from the studies in Asia suggested similar findings $[26,44,45]$. Low rates of control and treatment of hypertension have been considered as a major risk to increase cardiovascular diseases and stroke [46], which suggested the necessity of efficient implementation of proper training programs and offering essential services to health care services by doctors and health experts, while majority of patients with diagnosed hypertension showed poor control on their disease. This gap has also been reported in several other studies $[41,43,47]$. It seemed that the only way used to control hypertension by patients was taking prescribed medicines; they avoided self-care behaviors such as regular physical activities, good nutrition, and weight control.

Results from the present study reported higher treatment and control of hypertension in females in comparison to males, which was in accordance with the results from other studies [14, 43, 47, 48]. As the patients grew older, the treatment of hypertension improved. It seems that patients were more sensitive to their disease when they grew older and tried medicines to treat their disease. It corresponded to the results from other studies [41, 43, 47].

Another finding from the present study suggested a statistically significant correlation between hypertension control and patients education. The higher their education level, the higher the control rate among patients so that patients having university degrees showed higher control on their hypertension which was in accordance with results from other studies $[14,26,47,49]$, though it was different from study by CHPSNE which reported lower control on hypertension among individuals with lower education [50]. More than half of the participants reported average knowledge on hypertension, treatment pursuit, lifestyle, nutrition, and complication of hypertension. Only 25.2 percent of participants showed high knowledge on the disease. In comparison with other studies, the present study reported lower rates on the issue [34, 5153]. Parmar et al. showed good rates of knowledge on hypertension among participants [52]. The difference could result from high number of illiterate participants living in villages. 
TABLE 1: Percentage (\%) of treatment and control of hypertension among hypertensive adults $(N=1836)$.

\begin{tabular}{|c|c|c|c|c|c|c|c|}
\hline \multirow{2}{*}{ Variables } & \multirow{2}{*}{$N$} & \multicolumn{3}{|c|}{ Control } & \multicolumn{3}{|c|}{ Treatment } \\
\hline & & $n$ & $\%$ & $P$ & $n$ & $\%$ & $P$ \\
\hline \multicolumn{8}{|l|}{ Gender } \\
\hline Total & 1863 & 572 & 31.2 & \multirow{3}{*}{$P=0.796$} & 1373 & 74.8 & - \\
\hline Male & 722 & 222 & 30.7 & & 532 & 73.7 & \multirow{2}{*}{$P=0.383$} \\
\hline Female & 1114 & 350 & 31.4 & & 841 & 75.5 & \\
\hline \multicolumn{8}{|l|}{ Age groups } \\
\hline $39-30$ & 95 & 33 & 34.7 & \multirow{4}{*}{$P=0.135$} & 56 & 58.9 & \multirow{4}{*}{$P=0.000$} \\
\hline $49-40$ & 262 & 84 & 32.1 & & 180 & 68.7 & \\
\hline $59-50$ & 534 & 183 & 34.3 & & 401 & 75.1 & \\
\hline$\geq 60$ & 945 & 272 & 28.8 & & 736 & 77.9 & \\
\hline \multicolumn{8}{|l|}{ Region } \\
\hline Urban & 822 & 308 & 37.5 & \multirow{2}{*}{$P=0.000$} & 593 & 72.1 & \multirow{2}{*}{$P=0.019$} \\
\hline Rural & 1014 & 264 & 26 & & 780 & 76.9 & \\
\hline \multicolumn{8}{|l|}{ Marital status } \\
\hline Single & 25 & 10 & 40 & \multirow{3}{*}{$P=0.251$} & 16 & 64 & \multirow{3}{*}{$P=0.138$} \\
\hline Married & 1488 & 472 & 31.7 & & 1104 & 74.2 & \\
\hline Divorced and widowed/widower & 323 & 90 & 27.9 & & 253 & 78.3 & \\
\hline \multicolumn{8}{|l|}{ Education level } \\
\hline Illiterate & 1149 & 322 & 28 & \multirow{6}{*}{$P=0.000$} & 891 & 77.5 & \\
\hline Primary school & 362 & 129 & 35.6 & & 258 & 71.3 & \\
\hline Secondary school & 114 & 34 & 29.8 & & 76 & 66.7 & $P=0004$ \\
\hline High school & 46 & 22 & 47.8 & & 32 & 69.6 & $P=0.004$ \\
\hline Diploma & 90 & 28 & 31.1 & & 60 & 66.7 & \\
\hline University & 75 & 37 & 49.3 & & 56 & 74.6 & \\
\hline Job & & & & & & & \\
\hline Farmer & 205 & 58 & 28.9 & & 143 & 71.1 & \\
\hline Employed & 111 & 42 & 37.8 & & 84 & 75.7 & \\
\hline Retired & 184 & 64 & 34.8 & $P=0.351$ & 137 & 74.5 & $P=0.659$ \\
\hline Unemployed & 269 & 79 & 29.4 & & 197 & 73.2 & \\
\hline Housekeeper & 1071 & 329 & 30.7 & & 812 & 75.8 & \\
\hline Income & & & & & & & \\
\hline Poor & 1655 & 495 & 29.9 & & 1235 & 74.6 & \\
\hline Medium & 148 & 61 & 41.2 & $P=0.002$ & 112 & 75.7 & $P=0.833$ \\
\hline Good & 33 & 16 & 48.5 & & 26 & 78.8 & \\
\hline Family history of hypertension & & & & & & & \\
\hline Yes & 832 & 289 & 34.7 & $P-0003$ & 624 & 75 & $P-0845$ \\
\hline No & 1004 & 283 & 28.2 & $P=0.003$ & 749 & 74.6 & $P=0.845$ \\
\hline Physical activity & & & & & & & \\
\hline Yes & 512 & 174 & 34 & $P=0104$ & 380 & 74.2 & $P=0730$ \\
\hline No & 1324 & 398 & 30.1 & $P=0.104$ & 993 & 75 & \\
\hline Tobacco & & & & & & & \\
\hline Yes & 253 & 61 & 24.1 & $P-0 \Omega 00$ & 188 & 73.3 & $P=0852$ \\
\hline No & 1583 & 511 & 32.3 & $P=0.009$ & 1185 & 74.9 & $P=0.852$ \\
\hline Body mass index (BMI) & & & & & & & \\
\hline$\leq 18.5$ & 15 & 5 & 33.3 & & 11 & 73.3 & \\
\hline $25-18.5$ & 655 & 214 & 32.7 & $P=0.612$ & 493 & 75.3 & $P=0.980$ \\
\hline $30-25$ & 736 & 229 & 31.1 & $P=0.612$ & 547 & 74.3 & $P=0.980$ \\
\hline$\geq 30$ & 430 & 124 & 28.8 & & 322 & 74.9 & \\
\hline Duration of diagnosis & & & & & & & \\
\hline$\leq 5$ & 955 & 297 & 31.1 & & 669 & 70.1 & \\
\hline $5-9$ & 366 & 130 & 35.5 & & 293 & 80.1 & \\
\hline $10-14$ & 298 & 79 & 26.5 & $P=0.045$ & 235 & 78.9 & $P=0.000$ \\
\hline $15-19$ & 129 & 33 & 25.6 & & 97 & 75.2 & \\
\hline$\geq 20$ & 88 & 33 & 37.5 & & 79 & 89.8 & \\
\hline
\end{tabular}


TABLE 2: Percentage (\%) of knowledge of hypertension among hypertensive adults $(N=1836)$.

\begin{tabular}{|c|c|c|c|c|c|c|c|}
\hline \multirow{2}{*}{ Variables } & \multicolumn{2}{|c|}{ Weak } & \multicolumn{2}{|c|}{ Average } & \multicolumn{2}{|c|}{ Good } & \multirow{2}{*}{$P$} \\
\hline & $N$ & $\%$ & $N$ & $\%$ & $N$ & $\%$ & \\
\hline \multicolumn{8}{|l|}{ Gender } \\
\hline Male & 141 & 19.5 & 385 & 53.3 & 196 & 27.1 & \multirow{2}{*}{$P=0.261$} \\
\hline Female & 218 & 19.6 & 630 & 56.6 & 266 & 23.9 & \\
\hline \multicolumn{8}{|l|}{ Age groups } \\
\hline $39-30$ & 22 & 23.4 & 39 & 41.1 & 34 & 35.8 & \multirow{4}{*}{$P=0.019$} \\
\hline $49-40$ & 41 & 15.6 & 144 & 55 & 77 & 29.4 & \\
\hline $59-50$ & 100 & 18.7 & 300 & 56.2 & 134 & 25.1 & \\
\hline$\geq 60$ & 196 & 20.7 & 532 & 56.3 & 217 & 23 & \\
\hline \multicolumn{8}{|l|}{ Region } \\
\hline Urban & 149 & 18.1 & 452 & 55 & 221 & 26.9 & \multirow{2}{*}{$P=0.189$} \\
\hline Rural & 210 & 20.7 & 563 & 55.5 & 241 & 23.8 & \\
\hline \multicolumn{8}{|l|}{ Marital status } \\
\hline Single & 5 & 20 & 6 & 24 & 14 & 56 & \multirow{3}{*}{$P=0.004$} \\
\hline Married & 296 & 19.9 & 820 & 55.1 & 372 & 25 & \\
\hline Divorced and widowed/widower & 58 & 18 & 189 & 58.5 & 76 & 23.5 & \\
\hline \multicolumn{8}{|l|}{ Education level } \\
\hline Illiterate & 234 & 20.4 & 663 & 57.7 & 252 & 21.9 & \multirow{6}{*}{$P=0.000$} \\
\hline Primary school & 72 & 19.9 & 206 & 57.9 & 84 & 23.2 & \\
\hline Secondary school & 24 & 21.4 & 61 & 53.5 & 29 & 25.4 & \\
\hline High school & 4 & 8.7 & 22 & 47.8 & 20 & 43.5 & \\
\hline Diploma & 18 & 20 & 42 & 47.7 & 30 & 33.3 & \\
\hline University & 7 & 9.3 & 21 & 28 & 47 & 62.6 & \\
\hline \multicolumn{8}{|l|}{ Occupation } \\
\hline Farmer & 35 & 17.4 & 114 & 56.7 & 52 & 25.9 & \multirow{5}{*}{$P=0.001$} \\
\hline Employed & 13 & 11.7 & 55 & 49.5 & 43 & 38.7 & \\
\hline Retired & 34 & 18.5 & 88 & 47.8 & 62 & 33.7 & \\
\hline Unemployed & 63 & 23.4 & 151 & 56.1 & 55 & 20.4 & \\
\hline Housekeeper & 214 & 20 & 607 & 56.7 & 250 & 13.3 & \\
\hline \multicolumn{8}{|l|}{ Income } \\
\hline Weak & 322 & 20.1 & 20 & 13.5 & 7 & 21.7 & \\
\hline Average & 927 & 56 & 73 & 49.3 & 15 & 45.5 & $P=0.005$ \\
\hline Good & 396 & 23.9 & 55 & 32.2 & 11 & 33.3 & \\
\hline Family history of hypertension & & & & & & & \\
\hline Yes & 154 & 19.1 & 460 & 55.3 & 213 & 25.6 & $P=0.874$ \\
\hline No & 200 & 19.9 & 555 & 55.3 & 246 & 24.4 & $P=0.8 / 4$ \\
\hline Tobacco & & & & & & & \\
\hline Yes & 33 & 27.5 & 66 & 55 & 21 & 17.5 & $P=0.028$ \\
\hline No & 326 & 19 & 949 & 55.3 & 441 & 25.7 & \\
\hline Physical activity & & & & & & & \\
\hline Yes & 68 & 13.3 & 295 & 57.6 & 149 & 29.1 & $P=0000$ \\
\hline No & 291 & 22 & 720 & 54.4 & 313 & 23.6 & $P=0.000$ \\
\hline Body mass index (BMI) & & & & & & & \\
\hline$\leq 18.5$ & 4 & 26.7 & 7 & 46.7 & 4 & 26.7 & \\
\hline $25-18.5$ & 143 & 21.8 & 364 & 55.6 & 148 & 22.6 & $P=0157$ \\
\hline $30-25$ & 136 & 18.5 & 417 & 56.7 & 183 & 24.9 & $P=0.15 /$ \\
\hline$\geq 30$ & 76 & 17.7 & 227 & 52.7 & 127 & 29.5 & \\
\hline Duration of diagnosis & & & & & & & \\
\hline$\leq 5$ & 183 & 19.2 & 522 & 54.7 & 250 & 26.2 & \\
\hline $5-9$ & 77 & 21 & 204 & 55.7 & 85 & 23.2 & \\
\hline $10-14$ & 60 & 20.1 & 169 & 56.7 & 69 & 23.2 & $P=0.714$ \\
\hline $15-19$ & 22 & 17.1 & 77 & 59.7 & 30 & 23.3 & \\
\hline$\geq 20$ & 17 & 19.3 & 43 & 48.9 & 28 & 31.8 & \\
\hline
\end{tabular}


Another finding from the present study considered statistically significant correlation between patient's age and knowledge on the disease. It reported that the older the participants the less their knowledge on the issue, which was in accordance with results from other studies [34, 52]. It was concluded that age group of 30 to 39 had the higher knowledge on hypertension in comparison to other age groups, which could result from their higher education levels relative to other groups. Results from the present study in this regard suggested a meaningful relationship between education and knowledge: as the education among the patients improves, their knowledge on hypertension increases. It was in agreement with other studies $[34,52]$. Low knowledge levels on hypertension were in relation to old age, low levels of education, and low income. Lack of training materials, poor screening, and poor consistency of health team were reported in these groups. It seems necessary to create proper training materials by health experts to improve patients' knowledge and, also, increase treatment rates and control on patients.

The strength of the present study was investigating a large urban and rural population with high rates of responding. However, as over 80 percent of the participants were over 50 years old and there was not a normal coverage to all possible age groups, it was considered as a limitation to the study.

\section{Conclusion}

Considering the low rate of knowledge and control of patients on hypertension, health care providers should reinforce their activities to help to improve patients' knowledge level, especially among elders, through focusing on identifying risk factors to hypertension, regular drug intake, good nutrition, physical activity, and changing and informing lifestyles of patients with hypertension.

\section{Disclosure}

This paper is a part of the Ph.D. dissertation of health education and health promotion supported by Isfahan University of Medical Sciences and Yasuj University of Medical Sciences.

\section{Conflict of Interests}

The authors declare that there is no conflict of interests.

\section{Acknowledgments}

The authors would like to thank Deputy of Research of Isfahan University of Medical Sciences and Yasuj University of Medical Sciences for financial support.

\section{References}

[1] World Health Organization, Proceedings of the 15th Annual Conference of the Indian Society of Hypertension and 4th International CME on Atherosclerosis, Hypertension and Coronary Artery Disease, World Health Organization (WHO), New Delhi, India, 2005.
[2] World Health Organization, Global Recommendations on Physical Activity for Health, World Health Organization, Geneva, Switzerland, 1st edition, 2010.

[3] S. H. Habib and S. Saha, "Burden of non-communicable disease: global overview," Diabetes \& Metabolic Syndrome: Clinical Research and Reviews, vol. 4, no. 1, pp. 41-47, 2010.

[4] World Health Organization, The Global Burden of Disease: 2004 Update, WHO, 1st edition, 2008.

[5] S. G. Sepanlou, F. Kamangar, H. Poustchi, and R. Malekzadeh, "Reducing the burden of chronic diseases: a neglected agenda in Iranian health care system, requiring a plan for action," Archives of Iranian Medicine, vol. 13, no. 4, pp. 340-350, 2010.

[6] World Health Organization, Global Health Risks: Mortality and Burden of Disease Attributable to Selected Major Risks, WHO, 2013.

[7] M. Ezzati, A. D. Lopez, A. Rodgers, S. Vander Hoorn, and C. J. L. Murray, "Selected major risk factors and global and regional burden of disease," The Lancet, vol. 360, no. 9343, pp. 1347-1360, 2002.

[8] World Health Organization, "Causes of Death 2008," 2008, http://www.who.int/healthinfo/global_burden_disease/cod_ 2008_sources_methods.pdf.

[9] S. S. Lim, T. Vos, A. D. Flaxman et al., "A comparative risk assessment of burden of disease and injury attributable to 67 risk factors and risk factor clusters in 21 regions, 1990-2010: a systematic analysis for the Global Burden of Disease Study 2010," The Lancet, vol. 380, no. 9859, pp. 2224-2260, 2013.

[10] World Health Organization, "Report on the Regional Consultation on Hypertension Prevention and Control (Abu Dhabi, United Arab Emirates 20-22 December)".

[11] World Health Organization, "Global status report on no communicable diseases 2010," 2011.

[12] P. M. Kearney, M. Whelton, K. Reynolds, P. Muntner, P. K. Whelton, and J. He, "Global burden of hypertension: analysis of worldwide data," The Lancet, vol. 365, no. 9455, pp. 217-223, 2005.

[13] F. Amirkhizi, F. Siassi, S. Minaie, M. Jalali, M. A. Dorosty, and M. Chamari, "Assessment of blood pressure status and its relationship with anthropometric indices among women in rural areas of Kerman province, Iran," Yafteh, vol. 10, no. 2, pp. 31-38, 2009.

[14] A. Azizi, M. Abasi, and G. Abdoli, "The prevalence of hypertension and its association with age, sex and BMI in a population being educated using community-based medicine in Kermanshah: 2003," Iranian Journal of Endocrinology and Metabolism, vol. 10, no. 4, pp. 323-329, 2008.

[15] M. Ebrahimi, M. A. Mansournia, A. A. Haghdoost et al., "Social disparities in prevalence, treatment and control of hypertension in Iran: second National Surveillance of Risk Factors of Noncommunicable Diseases, 2006," Journal of Hypertension, vol. 28, no. 8, pp. 1620-1629, 2010.

[16] A. Esteghamati, A. Meysamie, O. Khalilzadeh et al., "Third national surveillance of risk factors of non-communicable diseases (SuRFNCD-2007) in Iran: methods and results on prevalence of diabetes, hypertension, obesity, central obesity, and dyslipidemia," BMC Public Health, vol. 9, no. 1, article 167, 2009.

[17] H. Fakhrzadeh, M. Nouri, R. Pour-Ebrahim, S. Ghotbi, R. Heshmat, and M. Bastanhagh, "Prevalence of hypertension and correlated risk factors among 25-64 aged inhabitants of Tehran University of medical sciences population lab region," Iranian Journal of Diabetes and Metabolism, vol. 3, pp. 37-43, 2004. 
[18] A.-A. Haghdoost, B. Sadeghirad, and M. Rezazadehkermani, "Epidemiology and heterogeneity of hypertension in Iran: a systematic review," Archives of Iranian Medicine, vol. 11, no. 4, pp. 444-452, 2008.

[19] B. Altun, M. Arici, G. Nergizoglu et al., "Prevalence, awareness, treatment and control of hypertension in Turkey (the PatenT study) in 2003," Journal of Hypertension, vol. 23, no. 10, pp. 18171823, 2005.

[20] M. Dorobantu, R. O. Darabont, E. Badila, and S. Ghiorghe, "Prevalence, awareness, treatment, and control of hypertension in romania: results of the SEPHAR Study," International Journal of Hypertension, vol. 2010, Article ID 970694, 6 pages, 2010.

[21] A. D. Efstratopoulos, S. M. Voyaki, A. A. Baltas et al., "Prevalence, awareness, treatment and control of hypertension in Hellas, Greece: the hypertension study in general practice in hellas (HYPERTENSHELL) national study," American Journal of Hypertension, vol. 19, no. 1, pp. 53-60, 2006.

[22] P. M. Kearney, M. Whelton, K. Reynolds, P. K. Whelton, and J. He, "Worldwide prevalence of hypertension: a systematic review," Journal of Hypertension, vol. 22, no. 1, pp. 11-19, 2004.

[23] H.-S. Lee, Y.-M. Park, H.-S. Kwon et al., "Prevalence, awareness, treatment, and control of hypertension among people over 40 years old in a rural area of South Korea: the Chungju Metabolic Disease Cohort (CMC) study," Clinical and Experimental Hypertension, vol. 32, no. 3, pp. 166-178, 2010.

[24] W. J. Ma, J. L. Tang, Y. H. Zhang et al., "Hypertension prevalence, awareness, treatment, control, and associated factors in adults in Southern China," American Journal of Hypertension, vol. 25, no. 5, pp. 590-596, 2012.

[25] K. Wolf-Maier, R. S. Cooper, J. R. Banegas et al., "Hypertension prevalence and blood pressure levels in 6 European countries, Canada, and the United States," The Journal of the American Medical Association, vol. 289, no. 18, pp. 2363-2369, 2003.

[26] T. Xu, Y. Wang, W. Li et al., "Survey of prevalence, awareness, treatment, and control of hypertension among Chinese governmental and institutional employees in Beijing," Clinical Cardiology, vol. 33, no. 6, pp. E66-E72, 2010.

[27] B. Y. Yuvaraj, M. R. Nagendra Gowda, and A. G. Umakantha, "Prevalence, awareness, treatment, and control of hypertension in rural areas of Davanagere," Indian Journal of Community Medicine, vol. 35, no. 1, pp. 138-141, 2010.

[28] T. G. Pickering, "Why are we doing so badly with the control of hypertension? Poor compliance is only part of the story," The Journal of Clinical Hypertension, vol. 3, no. 3, pp. 179-182, 2001.

[29] G. C. R. Roca, L. M. A. Ródenas, J. L. L. Caro et al., "Control of hypertension in elderly patients receiving primary care in Spain," Revista Española de Cardiología, vol. 58, no. 4, pp. 359366, 2005.

[30] Y. Wu, R. Huxley, L. Li et al., "Prevalence, awareness, treatment, and control of hypertension in China data from the China National Nutrition and Health Survey 2002," Circulation, vol. 118, no. 25, pp. 2679-2686, 2008.

[31] H.-R. Han, K. Chan, H. Song, T. Nguyen, J.-E. Lee, and M. T. Kim, "Development and evaluation of a hypertension knowledge test for Korean hypertensive patients," The Journal of Clinical Hypertension, vol. 13, no. 10, pp. 750-757, 2011.

[32] Y. Ostchega, C. F. Dillon, J. P. Hughes, M. Carroll, and S. Yoon, "Trends in hypertension prevalence, awareness, treatment, and control in older U.S. adults: data from the National Health and Nutrition Examination Survey 1988 to 2004," Journal of the American Geriatrics Society, vol. 55, no. 7, pp. 1056-1065, 2007.
[33] X. Li, N. Ning, Y. Hao et al., "Health literacy in rural areas of China: hypertension knowledge survey," International Journal of Environmental Research and Public Health, vol. 10, no. 3, pp. $1125-1138,2013$.

[34] S. Sanne, P. Muntner, L. Kawasaki, A. Hyre, and K. B. Desalvo, "Hypertension knowledge among patients from an urban clinic," Ethnicity and Disease, vol. 18, no. 1, pp. 42-47, 2008.

[35] J. J. Beunza, M. Á. Martínez-González, S. Ebrahim et al., "Sedentary behaviors and the risk of incident hypertension. The SUN Cohort," American Journal of Hypertension, vol. 20, no. 11, pp. 1156-1162, 2007.

[36] World Health Organization, "Obesity: preventing and managing the global epidemic: report of a WHO consultation," WHO Technical Report Series 894, World Health Organization, Geneva, Switzerland, 1999.

[37] S. B. Erkoc, B. Isikli, S. Metintas, and C. Kalyoncu, "Hypertension knowledge-level scale (HK-LS): a study on development, validity and reliability," International Journal of Environmental Research and Public Health, vol. 9, no. 3, pp. 1018-1029, 2012.

[38] N. C. Barengo, M. Kastarinen, R. Antikainen, A. Nissinen, and J. Tuomilehto, "The effects of awareness, treatment and control of hypertension on cardiovascular and all-cause mortality in a community-based population," Journal of Human Hypertension, vol. 23, no. 12, pp. 808-816, 2009.

[39] J. B. Jonas, V. Nangia, A. Matin, P. P. Joshi, and S. N. Ughade, "Prevalence, awareness, control, and associations of arterial hypertension in a rural central India population: the central India eye and medical study," American Journal of Hypertension, vol. 23, no. 4, pp. 347-350, 2010.

[40] I. I. Ulasi, C. K. Ijoma, B. J. C. Onwubere, E. Arodiwe, O. Onodugo, and C. Okafor, "High prevalence and low awareness of hypertension in a market population in Enugu, Nigeria," International Journal of Hypertension, vol. 2011, Article ID 869675, 5 pages, 2011.

[41] H. Wang, X. Zhang, J. Zhang et al., "Factors associated with prevalence, awareness, treatment and control of hypertension among adults in Southern China: a community-based," PLoS ONE, vol. 8, no. 5, Article ID e62469, 2013.

[42] K.-K. Zaw, T.-S. Latt, P.-P. Aung, T.-G. Thwin, and T.-K. Myint, "Prevalence of hypertension and its associated factors in the adult population in Yangon Division, Myanmar," Asia-Pacific Journal of Public Health, vol. 23, no. 4, pp. 496-506, 2011.

[43] C. K. Chow, K. K. Teo, S. Rangarajan et al., "Prevalence, awareness, treatment, and control of hypertension in rural and urban communities in high-, middle-, and low-income countries," Journal of the American Medical Association, vol. 310, no. 9, pp. 959-968, 2013.

[44] D. A. Ha, R. J. Goldberg, J. J. Allison, T. H. Chu, and H. L. Nguyen, "Prevalence, awareness, treatment, and control of high blood pressure: a population-based survey in Thai Nguyen, Vietnam," PLoS ONE, vol. 8, no. 6, Article ID e66792, 2013.

[45] J. Wang, L. Zhang, F. Wang, L. Liu, and H. Wang, "Prevalence, awareness, treatment, and control of hypertension in China: results from a national survey," American Journal of Hypertension, vol. 27, no. 11, pp. 1355-1361, 2014.

[46] World Health Organization, World Health Statistics 2012, World Health Organization, 2012, http://www.who.int/gho/publications/world_health_statistics/2012/en/index.html.

[47] M. Joffres, E. Falaschetti, C. Gillespie et al., "Hypertension prevalence, awareness, treatment and control in national surveys from England, the USA and Canada, and correlation with 
stroke and ischaemic heart disease mortality: a cross-sectional study," BMJ Open, vol. 3, no. 8, Article ID e003423, 2013.

[48] M. Pereira, N. Lunet, A. Azevedo, and H. Barros, "Differences in prevalence, awareness, treatment and control of hypertension between developing and developed countries," Journal of Hypertension, vol. 27, no. 5, pp. 963-975, 2009.

[49] Y. Wu, E. S. Tai, D. Heng, C. E. Tan, L. P. Low, and J. Lee, "Risk factors associated with hypertension awareness, treatment, and control in a multi-ethnic Asian population," Journal of Hypertension, vol. 27, no. 1, pp. 190-197, 2009.

[50] S. Tian, G.-H. Dong, D. Wang et al., "Factors associated with prevalence, awareness, treatment and control of hypertension in urban adults from 33 communities in China: the CHPSNE study," Hypertension Research, vol. 34, no. 10, pp. 1087-1092, 2011.

[51] A. R. Demaio, D. Otgontuya, M. de Courten et al., "Hypertension and hypertension-related disease in Mongolia; findings of a national knowledge, attitudes and practices study," BMC Public Health, vol. 13, no. 1, article 194, 2013.

[52] P. Parmar, G. B. Rathod, S. Rathod, R. Goyal, S. Aggarwal, and A. Parikh, "Study of knowledge, attitude and practice of general population of Gandhinagar towards hypertension," International Journal of Current Microbiology and Applied Sciences, vol. 3, no. 8, pp. 680-685, 2014.

[53] X. Zhang, M. Zhu, H. H. Dib et al., "Knowledge, awareness, behavior (KAB) and control of hypertension among urban elderly in Western China," International Journal of Cardiology, vol. 137, no. 1, pp. 9-15, 2009. 


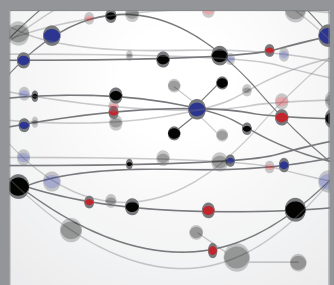

The Scientific World Journal
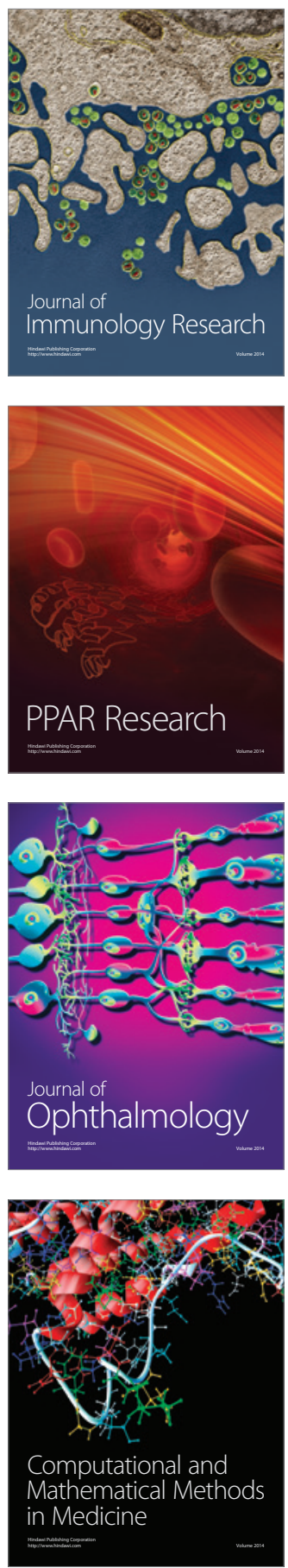

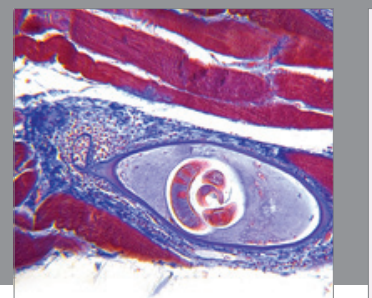

Gastroenterology

Research and Practice
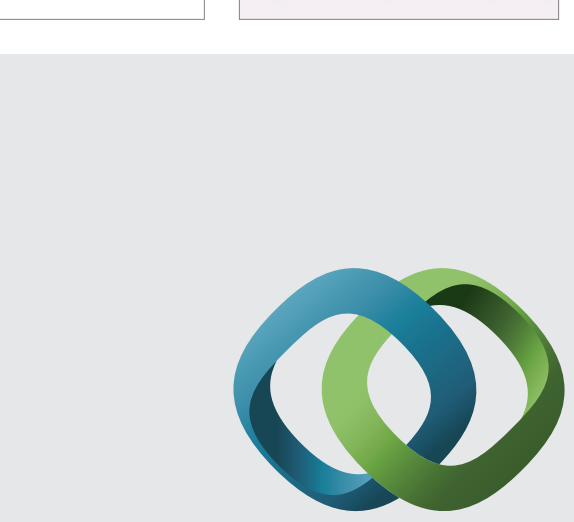

\section{Hindawi}

Submit your manuscripts at

http://www.hindawi.com
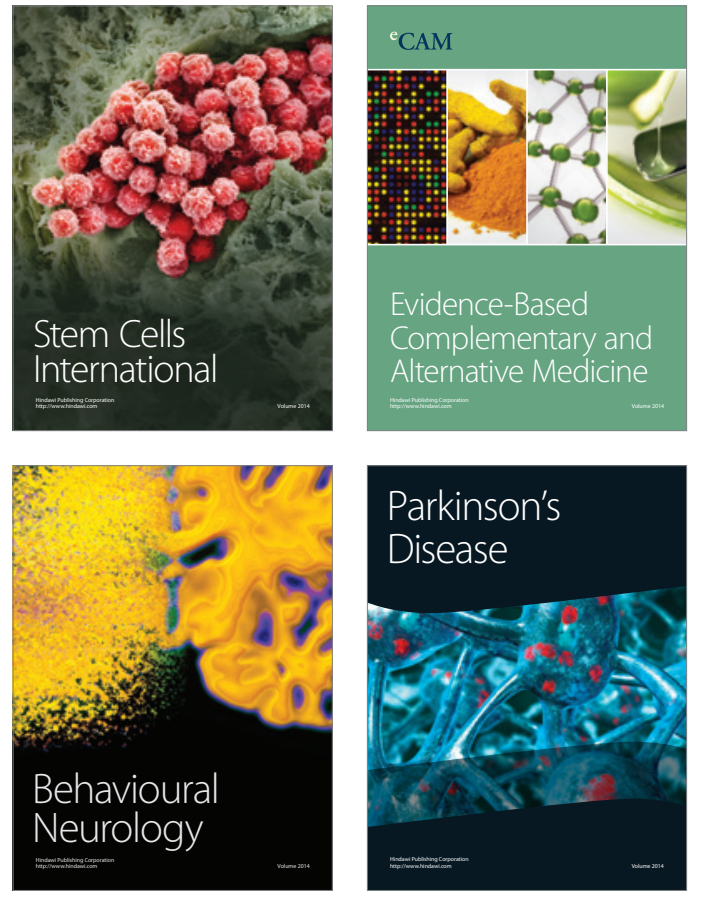
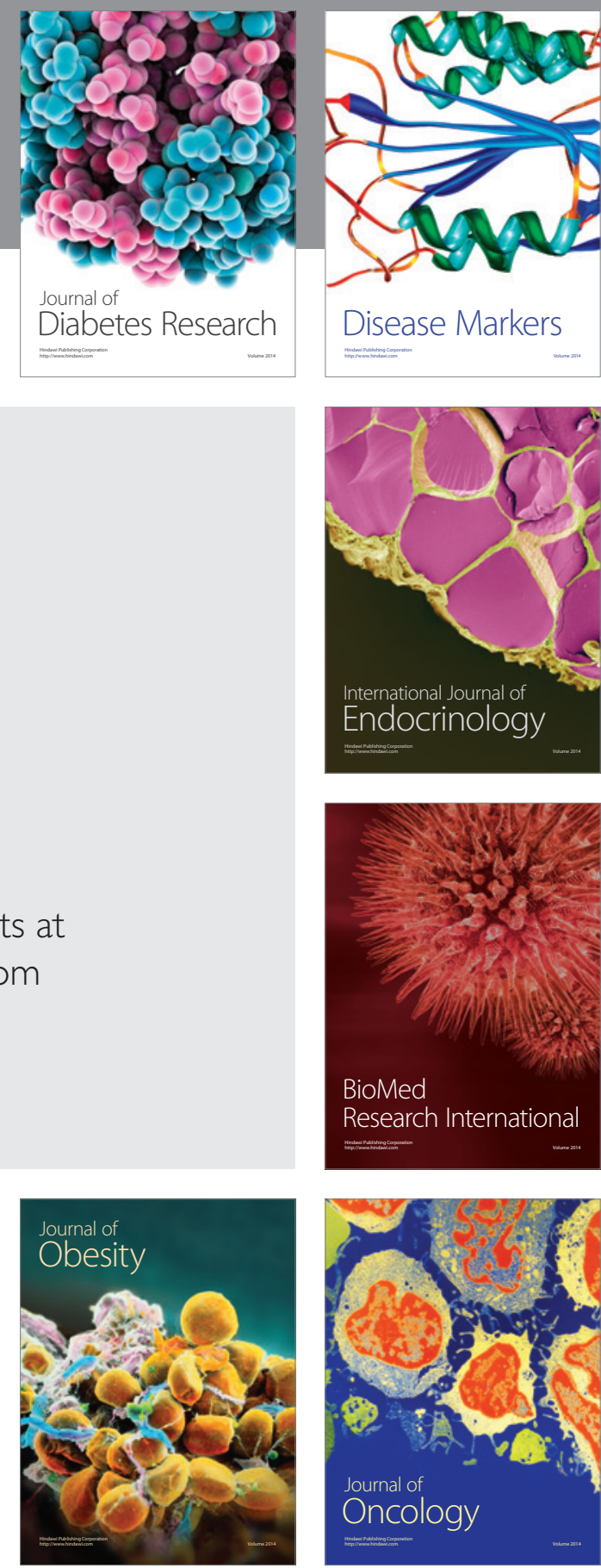

Disease Markers
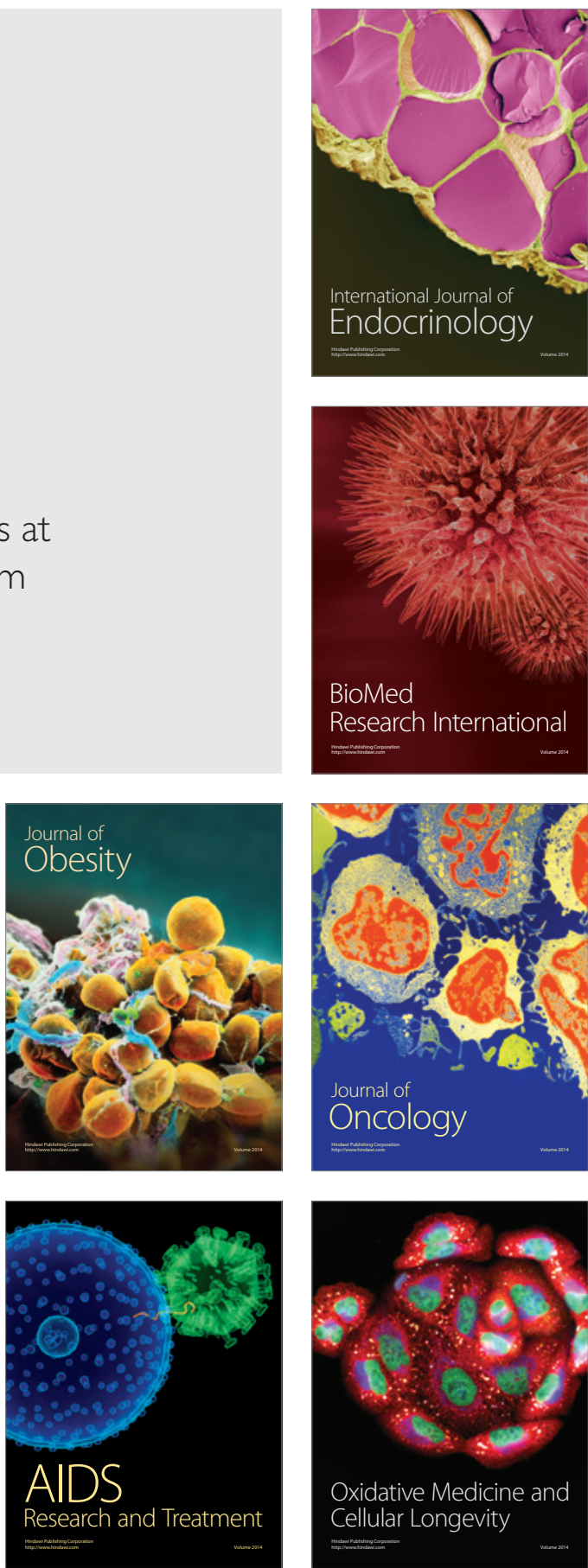